\title{
SISTEM INFORMASI EKSEKUTIF DASHBOARD MONITORING HASIL PRODUKSI PADA PT KMK GLOBAL SPORTS MENGGUNAKAN AUTOMATIC TIMMER
}

\author{
Henderi $^{1}$ \\ Winarno $^{2}$ \\ Didi Rahmat ${ }^{3}$
}

Dosen Magister Teknik Informatika ${ }^{1,2}$, Mahasiswa Magister Teknik Informatika ${ }^{3}$ e-mail: henderi@raharja.info ${ }^{1}$,winarno@ raharja.info ${ }^{2}$, didi.rahmatsaputra@ raharja.info $^{3}$

\begin{abstract}
ABSTRAKSI
Prototipe executive dashboard monitoring produksi untuk pengambil keputusan pada PT KMK Global Sports merupakan penelitian yang dilakukan dalam rangka mengimplementasikan sebuah sistem executive dashboard yang dapat membantu manajemen PT KMK Global Sports mengambil keputusan dalam kegiatan produksi. Pada saat ini PT KMK Global Sports belum memiliki pengelolaan data/informasi pembelian material dan proses produksi sepatu secara cepat dan tepat untuk keperluan rekapitulasi kegiatan harian dan bulanan, sering terjadinya keterlambatan dalam pembelian material, serta infrastruktur jaringan komputer, perangkat keras dan perangkat lunak yang belum memadai. Pembangunan executive dashboard dibangun berdasarkan model pengembangan dashboard berbasis user centered design. Pengembangan sistem executive dashboard monitoring produksi menggunakan model prototipe berbasis SDLC (System Development Life Cycle) dan OOAD (Object-oriented analysis and design). Prototipe diuji dengan menggunakan pengujian ISO 9126 yaitu black box testing. Hasil dari penelitian ini adalah sebuah prototipe executive dashboard monitoring produksi yang dapat dijadikan sebagai salah satu referensi pimpinan PT KMK Global Sports dalam mengambil keputusan dan diharapkan dapat menjadi referensi, contoh bagi lembaga atau perusaahan di kota lain.
\end{abstract}

Kata Kunci: Dashboard,Monitoring, ISO 9126, black box testing.

\section{ABSTRACT}

The prototype executive dashboard production monitoring for decision makers at PT KMK Global Sports is a research conducted in order to implement an executive dashboard system that can help the management of PT KMK Global Sports make decisions in production activities. At the moment PT KMK Global Sports does not have the data / information management for the purchase of materials and footwear production processes quickly and accurately for the purposes of recapitulation of daily and monthly activities, frequent delays in material purchases, and computer network infrastructure, hardware and software that have not adequate. Construction of an executive dashboard is built based on a user centered design based dashboard development model. The development of a production monitoring executive dashboard system uses an SDLC-based prototype model (System Development Life Cycle) and OOAD (Object-oriented analysis and design). The prototype was tested using ISO 9126 testing, namely black box testing. The results of this study are a prototype executive production dashboard monitoring that can be used as one of the references of the leadership of PT KMK Global Sports in making decisions and is expected to be a reference, an example for institutions or companies in other cities.

Keywords: Dashboard,Monitoring, ISO 9126, black box testing. 


\section{PENDAHULUAN}

Belakangan ini, teknologi informasi berkembang pesat diberbagai segi kehidupan masyarakat. Begitu juga dengan sistem informasi yang sudah banyak digunakan hampir di seluruh instansi baik pemerintah maupun swasta, salah satunya perusahaan manufacture Contoh sistem informasi yang digunakan di perusahaan adalah Sistem Perencanaan Sumber Daya Perusahaan (ERP). Sistem ERP merupakan suatu sistem informasi terintegrasi yang sudah digunakan oleh perusahaan manufacture untuk menangani keseluruhan proses manajemen perusahaan mulai dari pembelian material hingga export. PT.KMK Global Sports merupakan salah satu perusahaan yang terdapat di kabupaten tangerang yang sudah memanfaatkan sistem ERP. Sistem yang digunakan PT.KMK Global Sports terdiri dari beberapa role atau pengguna, diantaranya purchasing, gudang, production dan export.

Setiap harinya, kegiatan yang ada di perusahaan tersebut baik Purchasing, Gudang, Production dan Export. diolah dengan Sistem Perencanaan Sumber Daya sehingga setiap harinya, data akan bertambah banyak. Data yang akan bertambah tersebut belum diolah secara optimal sehingga jika pimpinan akan melakukan pengontrolan suatu bagian atau akan mengetahui secara keseluruhan kegiatan di perusahaan tersebut secara akurat, relevan dan real time belum dapat ditangani secara maksimal oleh sistem ini. Sehingga dibutuhkan sebuah sistem pengembangan dari ERP untuk menangani masalah tersebut.

Sistem informasi dashboard merupakan sebuah pengembangan dari sistem ERP yang disajikan dalam bentuk visual, on line, relevan dan mudah dipahami oleh para pemimpin perusahaan yang cocok untuk menangani masalah yang ada di PT KMK Global Sports. Sehingga dengan adanya sistem informasi dashboard ini dapat membantu para pimpinan perusahaan untuk melakukan proyeksi dalam memonitor hasil produksi,kekurangan material,dan jadwal export dalam rangka meningkatkan kualitas pelayanan perusahaan.

Pengertian produksi yaitu hasil akhir dari proses atau aktivitas ekonomi dengan memanfaatkan beberapa masukan atau input. Dengan pengertian ini dapat dipahami bahwa kegiatan produksi diartikan sebagai aktivitas dalam menghasilkan output dengan menggunakan teknik produksi tertentu untuk mengolah atau memproses input sedemikian rupa (1).

Produksi merupakan hasil akhir dari proses atau aktivitas ekonomi dengan memanfaatkan beberapa masukan atau input. Produksi atau memproduksi menambah kegunaan suatu barang. Kegunaan suatu barang akan bertambah bila memberikan manfaat baru atau lebih dari bentuk semula. Lebih spesifik lagi produksi adalah kegiatan perusahaan dengan mengkombinasikan berbagai input untuk menghasilkan output dengan biaya yang minimum (2).

Dashboard adalah alat penting untuk memonitor keadaan sehari-hari suatu organisasi dan sebagai alat penghubung tunggal yang digunakan untuk membuat keputusan dan mempuyai akses untuk mengunci indikator kinerja/KPIs, dashboard seperti sebuah jaringan lokal yang eksekutif, dimana semua kegiatan ditampilkan (3).

Dashboard memberikan sebuah tampilan panel secara visual dari informasi informasi penting yang dibutuhkan, terkonsolidasi dan tersusun dalam sebuah tampilan layar dimana informasi tersebut dapat dicerna secara sekilas dan mudah untuk diekplorasi lebih dalam (4).

Fitur yang paling khas dari dashboard adalah tiga lapisan atas informasi, yaitu monitoring, analisis dan manajemen. Fungsi dashboard bagi manajemen adalah menampilkan data operasional yang rinci yang mengidentifikasi tindakan yang harus dilakukan manajemen untuk menyelesaikan masalah (4).

Dari beberapa difinisi Produksi adalah proses untuk menciptakan, menghasilkan, dan membuat. Kegiatan produksi tidak akan dapat dilakukan kalau tidak ada bahan yang memungkinkan dilakukannya proses produksi itu sendiri. Untuk bisa melakukan produksi, orang memerlukan tenaga manusia, sumber-sumber alam, modal dalam segala bentuknya, serta kecakapan.

ISO 9126 merupakan sebuah panduan evaluasi standar dari sebuah produk perangkat lunak yang dikeluarkan oleh badan internasional untuk standardisasi. Pada ISO 9126 didefinisikan enam karakteristik yang menggambarkan, mengukur kualitas sebuah perangkat unak (sistem), yaitu: kemampuan functionality), kehandalan(reliability), kegunaan(usability), efisiensi(efficiency), pemeliharaan(maintenability), portabilitas (portability) 


\section{METODE PENELITIAN}

\subsubsection{Devinisi Excecutive Dashboard}

Soleh, Oleh (2013), mengatakan dashboard adalah alat penting untuk memonitor keadaan sehari-hari suatu organisasi dan sebagai alat penghubung tunggal yang digunakan untuk membuat keputusan dan mempuyai akses untuk mengunci indikator kinerja/KPIs, dashboard seperti sebuah jaringan lokal yang eksekutif, dimana semua kegiatan ditampilkan.

Dashboard memberikan sebuah tampilan panel secara visual dari informasi informasi penting yang dibutuhkan, terkonsolidasi dan tersusun dalam sebuah tampilan layar dimana informasi tersebut dapat dicerna secara sekilas dan mudah untuk diekplorasi lebih dalam (Turban, 2011: 408).

Fitur yang paling khas dari dashboard adalah tiga lapisan atas informasi, yaitu monitoring, analisis dan manajemen. Fungsi dashboard bagi manajemen adalah menampilkan data operasional yang rinci yang mengidentifikasi tindakan yang harus dilakukan manajemen untuk menyelesaikan masalah (eckerson, dikutip dalam Turban, 2011: 409).

Jadi executive dashboard merupakan sebuah alat bantu dalam bentuk sistem yang menampilkan data/informasi untuk mempermudah manajemen membaca aktifitas yang telah dilakukan, menganalisa dan memprediksi data yang akan datang, executive dashboard akan lebih mudah dipahami manajemen jika menggunakan grafik/gambar dibanding melihat dalam bentuk angka dan tabel.

2.1.2. Metodologi Pengembangan Dashboard

Henderi (2013), mengatakan pengembangan digital dashboard dapat menggunakan beberapa macam metodologi, yaitu:

1. Joint Application Development (JAD)

2. Prototyping

3. Services Oriented Architecture (SOA)

4. Metode lainnya.

Metodologi Prototyping dan JAD paling banyak digunakan. Metodologi JAD banyak dipilih karena lebih praktis, bisa dilakukan secara bersamaan dengan pengembangan sistem lainnya.

Soleh, Oleh dkk (2013), mengatakan metodologi pengembangan dashboard ada tiga macam, antara lain: metodologi pureShare, metodologi neotix dan metodologi brihtpoint. Sedangkan Padita, Anderson dkk (2015), mengatakan pengembangan dashboard dapat menggunakan metode user centered design.

Dari berbagai macam metodologi pengembangan dashboard, digunakan metodologi pengembangan user centered design karena merupakan sebuah metodologi pengembangan dashboard yang didasarkan pada fokus dan efektivitas hasil yang akan dicapai. Kunci keberhasilan pengembangan dashboard tergantung antarmuka dan informasi yang dihasilkan harus sesuai dengan kebutuhan pengguna, harus dapat dengan mudah dipahami serta dipersepsi dengan benar oleh penggunanya.

2.1.3. Pengacuan Pustaka

1. Penelitian yang dilakukan oleh Henderi dan Ruli Suprianti, yang berjudul Model Sistem Executive Digital Dashboard UntukPerguruan Tinggi pada Jurnal KNSI No. 144, tahun 2014. Penelitian ini mengenai pentingnya sistem executive dashboard untuk perguruan tinggi. Tujuan penelitian ini adalah mengolah data yang dihasilkanoleh sebuah perguruan tinggi yang cenderung berlebihan. Hasil penelitian adalah sebuah sistem dashboard dengan software Fusionchart yang disebut EDDU sebagai sebuah visualisasi informasi KPI(5).

2. Penelitian yang dilakukan oleh Anderson Padita, Hanung Adi Nugroho, dan Paulus Insap Santosa, yang berjudul Model Pengembangan Dashboard Berbasis User-Centered Design pada Seminar Nasional Ilmu Komputer (SNIK 2015), tahun 2015. Penelitian ini membahas tentang pengembangan dashboard yang menggunakan metode user centered design, dengan menggunakan 5 fase utama yaitu: identifikasi kebutuhan,analisis dan perencanaan, perancangan pengujian\&evaluasi dan implementasi(6). 
3. Penelitian yang dilakukan oleh Pawan Chowdhary, Themis Palpanas, Florian Pinel, Shyh-kwei Chen, Fredrick Y. Wu, yang berjudul Model-Driven Dahsboards for Business Performance Reporting pada Jurnal IEEE, DOI:10.1109/EDOC, tahun 2006. Peneliti mengenai sebuah pendekatan untuk develop dashboard yang model-driven.Tujuan penelitian adalah dihasilkannya sebuah usulan pembangunan dashboard yang dapat diintegrasikan dengan model kinerja bisnis. Hasil dari penelitian ini adalah usulan teknik desain dashboard model-driven yang efisien dan efektif. Peneliti menerapkan teknik merancang dan menggunakan dashboard(10).

4. Penelitian yang dilakukan oleh Mohan S Gounder, Vani Vasundevan Iyer, dan Abdul aziz Al Mazyad, yang berjudul A Survey on Busines Intelligence Tools for University Dashboard Development pada Jurnal IEEE, DOI:10.1109/ICBDSC.21 6.7460347, Date Of Conference tahun 2016. Penelitian Ini membahas mengenai survei rinci pada alat bantu Business Intelligence (BI). Untuk mengembangkan sebuah dashboard dalam pembangunan khusus sebuah akademik. Tujuan Penelitian adalah membahas tools pengembangan dashboard mana yang paling sesuai untuk pengembangan sebuah system dashboard di universitas. Hasil dari penelitian ini menginformasikan bahwa tools yang ada saat ini seperti Spago BI, Tableau, Pentaho, Qliksense, Jaspersoft Dan Jedox(11).

5. Penelitian yang dilakukan oleh J Sengol Mary dan S Usha, yang berjudul Web Based Document Management Systems in Life Science Organization pada IEEE Journal, DOI:10.1109/GET.2015.74 53826 Date of Conference tahun 2015. Penelitian ini membahas mengenai solusi Document Management System (DMS). Tujuan penelitian adalah didapat sebuah rekomendasi solusi DMS yang dapat mengotomatisasi/memudahkan proses pengelolaan dokumen untuk memastikan kepatuhan dengan regulasi perdokumen yang berlaku. Hasil penelitian ini berupa struktur pengembangan DMS(12).

6. Penelitian yang dilakukan oleh Enrico De Giovanni, Sergio Flesca, Antonietta Folio, dkk, yang berjudul Digital Document Copies and Duplicatespada Fifth International Conference on Digital Information Processing and Communications (ICDIPC), tahun 2015. Penelitian ini menggambarkan masalah yang signifikandiperkenalkan oleh kerangka normatif yang ada di Italia saatini terutama di bidang E-Government mengenai dokumen digital. Tujuan penelitian ini fokus pada nilai pembuktian dari kertas dan dokumen digital dan khususnya pada masalah salinan dokumen digital dan duplikat. Kesimpulan dari penelitian ini adalah: tidak sejalannya regulasi yang berlaku pada dokumen digital(13).

7. Penelitian yang dilakukan oleh S.F Ochoa, P.O Rossel, dan M.C Bastarrica, yang berjudul A Software Architecture to Support Digital Document Interchange for The Chilean Govermentpada Jurnal IEEE. DOI:10.1109/ICACT, tahun 2015. kualitas pelayanan yang dapat diberikan dengan integrasi sistem manajemen dokumen heterogen, dan platform seperti apa yang dibutuhkan untuk pemecahan DMS. Hasil daripenelitian ini berupa informasi bahwa Menerapkan solusi e-Government selalu melibatkan tantangan penting yang terkait dengan perubahan organisasi, menyesuaikan sistem warisan, pengembangan waktu/biaya dan ketersediaan penyedia layanan(14). 


\section{HASIL DAN PEMBAHASAN}

\section{Usecase Diagram Sistem yang Diusulkan}

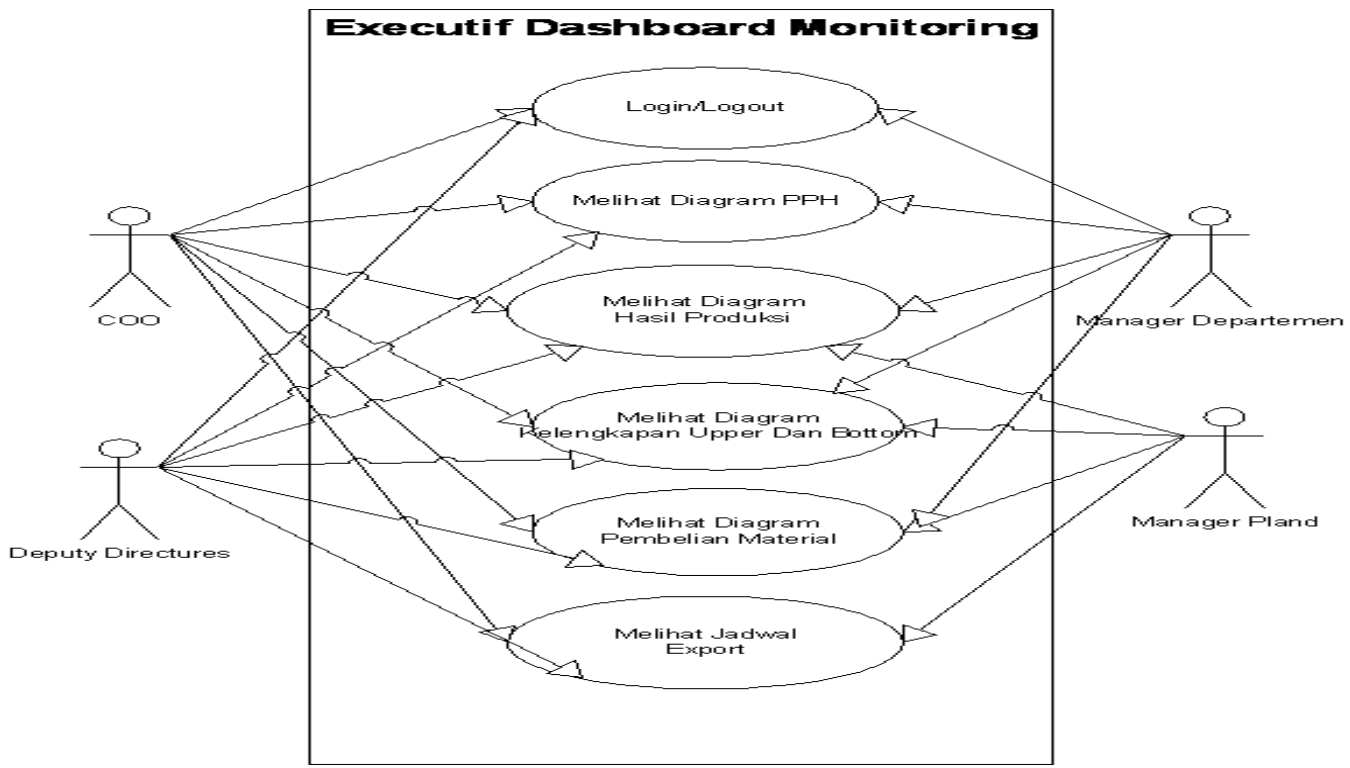

Gambar 1. Usecase diagram sistem Eksekutif Dashboard

Kelemahan pada sistem yang berjalan ada pada setiap proses yanng digambarkan kerena setiap proses memerlukan waktu untuk membuat rekapitulasi informasi agar dapat dilaporkan kepada COO atau pimpinan perusahaan. Setelah mengetahui diagram use case sistem berjalan di atas, dapat dijelaskan dalam daftar use case sebagaimana Tabel 4.2 berikut ini:

Tabel 1. Daftar UseCase diagram eksekutif dashboard

\begin{tabular}{|c|c|c|}
\hline \multirow[t]{2}{*}{1} & Use Case & Diagram PPH (Per Per Hour) \\
\hline & Description & $\begin{array}{l}\text { Use case ini memungkinakan pengguna untuk melihat berapa } \\
\text { rata -rata kecepatan produksi sepatu per jam informasi ini dapat } \\
\text { di gunakan untuk menentukankebutuhan untuk over-time(jam } \\
\text { lembur) jika di perlukan }\end{array}$ \\
\hline & Actor & COO,DeputyDirectures,Manager Pland,Manager Departement \\
\hline & Pre-Condition & $\begin{array}{l}\text { Pada saat sistem pertama kali diakses menggunakan browser } \\
\text { (web based), pengguna akan diminta memasukan nama user dan } \\
\text { password agar dapat masuk kedalam sistem Executive } \\
\text { Dashboard Monitoring Produksi PT KMK Global Sports. }\end{array}$ \\
\hline \multirow[t]{4}{*}{2} & Use Case & Diagram Produksi \\
\hline & Description & $\begin{array}{l}\text { Use case ini memungkinakan pengguna untuk melihat berapa } \\
\text { persen hasil produksi dan total hasil produksi diagram ini } \\
\text { berfungsi untuk menentukan kurang /lebih hasil produksi di } \\
\text { bandingkan dengan kebutuhan export }\end{array}$ \\
\hline & Actor & COO,DeputyDirectures,Manager Pland,Manager Departement \\
\hline & Pre-Condition & $\begin{array}{l}\text { Pada saat sistem pertama kali diakses menggunakan browser } \\
\text { (web based), pengguna akan diminta memasukan nama user dan } \\
\text { password agar dapat masuk kedalam sistem Executive } \\
\text { Dashboard Monitoring Produksi PT KMK Global Sports. }\end{array}$ \\
\hline
\end{tabular}




\section{Class Diagram Sistem}

Diagram class adalah diagram yang menggambarkan class-class yang ada pada sebuah sistem dan menggambarkan saling keterhubungannya logik. Diagram class juga menggambarkan struktur database dari sebuah sistem. Eksekutif dashboard monitoring produksi pengambilan keputusan PT KMK Global Sport dibangun dengan Database, yang terdiri dari beberapa class, sebagaimana tabel 4.10 , gambar 4.10 berikut:

Tabel 2. Database Dashboard Eksekutif Monitoring Produksi

\begin{tabular}{|c|c|c|}
\hline \multirow[b]{2}{*}{ No } & \multicolumn{2}{|c|}{ Class database Executif Dashboard Monitoring Produksi } \\
\hline & Nama Tabel & Keterangan \\
\hline & & \\
\hline 1 & sum_pemb_material & $\begin{array}{l}\text { Tabel yang berisi data rekapitulasi pembelian } \\
\text { material per hari dan perbulan }\end{array}$ \\
\hline 2 & sum_terima_material & $\begin{array}{l}\text { Tabel yang berisi data rekapitulasi } \\
\text { penerimaan material per hari dan perbulan }\end{array}$ \\
\hline 3 & Sum_pakai_material & $\begin{array}{l}\text { Tabel yang berisi data rekapitulasi } \\
\text { pemakaian material per hari dan perbulan }\end{array}$ \\
\hline 4 & Sum_pph & $\begin{array}{l}\text { Tabel yang berisi data hasil produksi yang } \\
\text { sudah di calculasi menjadi kecepatan produksi }\end{array}$ \\
\hline 5 & Sum_hasil_produksi & $\begin{array}{l}\text { Tabel yang berisi data total hasil produksi dan } \\
\text { perbulan/ }\end{array}$ \\
\hline 6 & Sum_hasil_export & $\begin{array}{l}\text { Tabel yang berisi data total hasil export per } \\
\text { hari dan perbulan }\end{array}$ \\
\hline 7 & Sum_barang_jadi & $\begin{array}{l}\text { Table yang berisi data hasil produksi yang } \\
\text { sudah ada di dalam gudang barang jadi yang } \\
\text { siap untuk export }\end{array}$ \\
\hline 8 & Mst_plan & $\begin{array}{l}\text { Tabel yang berisi data tentang identitas } \\
\text { plan/gedung produksi }\end{array}$ \\
\hline 9 & Mst_line & $\begin{array}{l}\text { Tabel yang berisi data tentang identitas Line } \\
\text { produksi di dalam sebuah pland }\end{array}$ \\
\hline 10 & Mst_process & $\begin{array}{l}\text { Tabel yang berisi data tentang identitas proses } \\
\text { yang ada dalam produksi }\end{array}$ \\
\hline
\end{tabular}

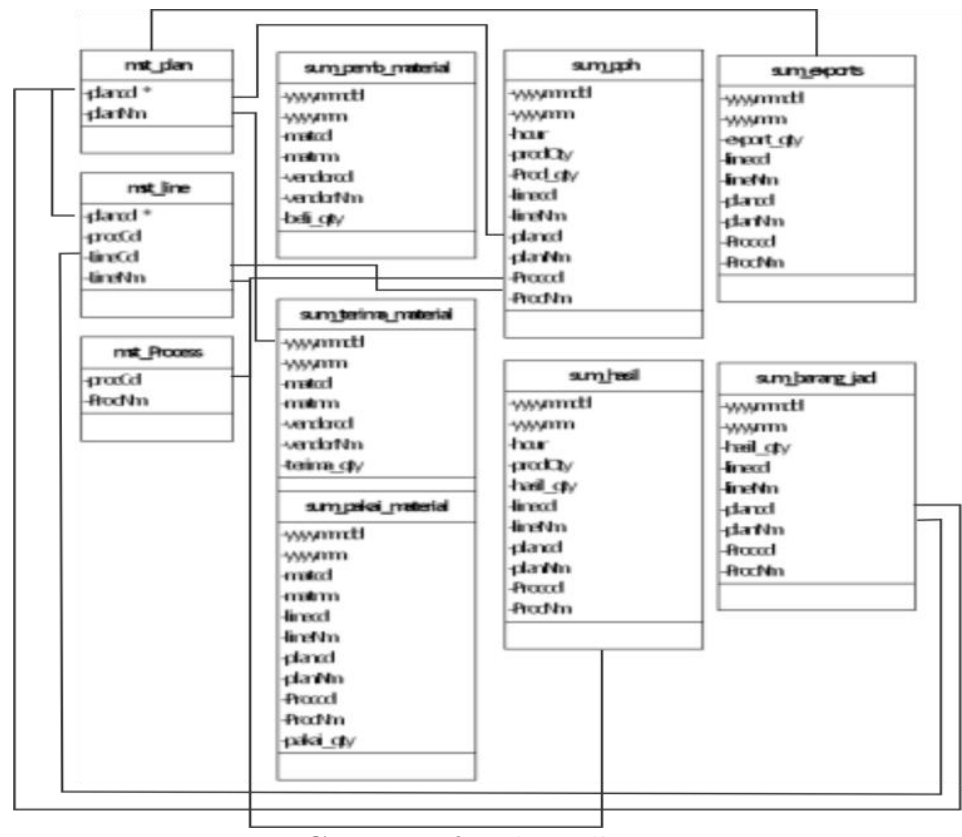

Gambar 2. Class diagram 


\section{Metode Pengumpulan Data}

Metode pengumpulan data menggunakan stored procedure yang di tanam dalam masing masing database kemudian dikirimkan ke data warehose yang ada di perusahaan seperti gambar berikut :

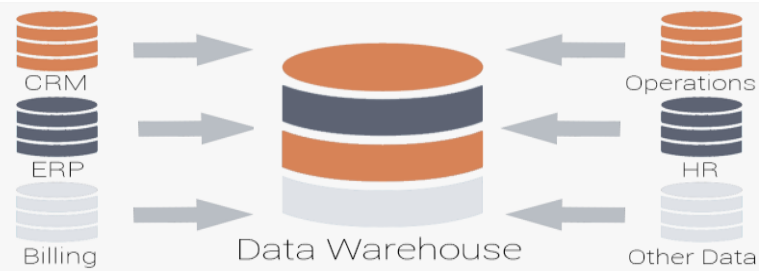

Gambar 3. Proses pemindahan data ke datawarehose

Data dari masing masing database dikirm ke data warehose agar ketika menampilkan report dari datawarehose tidak memerlukan query yang memakan banyak waktu,sehingga dapat menampilkan data secara cepat.Kemudian data yang telah berada di dalam datawarehose diubah dalam bentuk format JSON agar dashboard dapat dengan mudah menarik data dari server datawarehose.

\section{IMPLEMENTASI}

Sistem ini masih dalam tahap ujicoba secara lokal/internal pada PT. KMK Global Sports, pada sistem ini pengguna dapat memonitoring proses produksi melalui tampilan dashboard. Berikut screenshot dari sistem yang diusulkan:

a. Tampilan Dashboard

Apabila seorang pengguna diberi akses untuk memasuki sistem, maka pengguna akan dapat melihat tampilan utama sistem sebagaimana gambar 5 berikut ini:

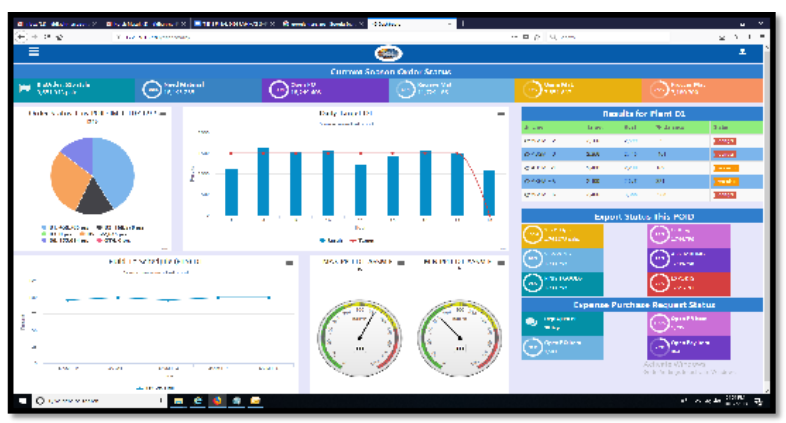

Gambar 4. Tampilan eksekutif dashboard

\section{b. Tampilan Dashboard Detail}

Dashboard material terdiri dari beberapa grafik yang berisi informasi yang diperlukan sistem dan menjadi acuan pengguna pada saat melakukan transaksi pembelian ,penerimaan dan penggunaan material yang dikelola oleh PT KMK Global Sports, dashboard material gambar 6 terdiri dari:

1. Dashboard jumlah order dan kebutuhan material,dashboard ini menampilkan kebutuhan material dan jumlah order yang telah di terima oleh perusahaan.Jumlah order yang di tampilkan digunakan management untuk mengetahui apabila jumlahnya kurang dari 3.000.000 pasang makaharus mengurangi jumlah ofertime dan harus melakukan efesiensi terhadap jam kerja dan jumlah tenaga kerja.

2. Dashboard jumlah kebutuhan material di gunakan untuk mengethui persentasi jumlah kebutuhan material yang harus di beli oleh manajemen jika persentase nya kurang dari $100 \%$ maka harus ada pengecekan di bagian purchasing tentang kebutuhan material

3. Dashboard jumlah dibuatkan Purchase Order (PO) digunakan untuk mengetahui berapa jumlah kebutuhan material yang sudah di PO.jika jumlah persentase kurang dari 100\% maka masih ada kekurangan dalam pembuatan PO untuk kebutuhan material 
4. Dashboard jumlah penerimaan barang (GRN) digunakan untuk mengetahui berapa jumlah PO yang sudah di terima oleh perusahaan .Untuk penerimaan material ini mengikuti jumlah hari dalam satu bulan dalam membuat persentasi jika petengehan bulan artinya jumlah persentase nya 50\% namun ketika mendekati akhir bulan maka persentase nya harus $100 \%$ jika kurang maka ada keterlambatan dalam penerimaan material.

5. Dashboard jumlah penggunaan material (MR) digukan untuk mengetahui berapa jumlah pemakaian material yang digunakan untuk mebuat sepatu. Untuk penggunan material ini mengikuti jumlah hari dalam satu bulan dalam membuat persentasi jika petengehan bulan artinya jumlah persentase nya 50\% namun ketika mendekati akhir bulan maka persentase nya harus $100 \%$ jika kurang maka ada keterlambatan dalam penggunaan material.

6. Dashboard jumlah material yang di proses (GIN) digukan untuk mengetahui berapa jumlah pemakaian material yang sudah di proses untuk membuat sepatu. Untuk penggunan material ini mengikuti jumlah hari dalam satu bulan dalam membuat persentasi jika petengehan bulan artinya jumlah persentase nya 50\% namun ketika mendekati akhir bulan maka persentase nya harus $100 \%$ jika kurang maka ada keterlambatan dalam penggunaan material.

7. Dashboard order status digunakan untuk mengetahu jumlah dan jenis order yang ada pada setiap gedung (pland) produksi.Informasi ini digunakan untuk mengambil keputusan pemindahan line di masing masing gedung produksi ini di karenakan setiap jenis sepatu mempunyai proses pengerjaan yang berbeda jadi management perusahaan harus dapat mengambil keputusan apakah line di dalam sebuah gedung harus pindah ke gedung lain atau tidak.

8. Dashboard daily target digunakan untuk mengetahui dalam satu gedung produksi mencapai target harian atau tidak.Jika tidak mencapai target maka management akan memeriksa line yang ada di produksi untuk mengetahui masalah yang sedang terjadi sehingga mengakibatkan tidak tercapainya target harian.

9. Dashboard result pland menggambarkan hasil produksi di setiap line dengan memunculkan status masing masing line.Jika status warning maka belum mencapai target,jika danger maka melebihi target ,dan jika success maka suddah mencapai target.

10.Dashboard build to schedjule (BTS) menampilkan data kesesuaian antara planing dan real production data ini berfungsi untuk menentukan line yang harus di berikan offer time dikarenakan ketidak sesuaian planning dan real product.Semakin tinggi nilai BTS line maka tidak di butuhkan offer time untuk line tersebut.

11. Dashboard Per Per Hours (PPH) ,menampilkan informasi tentang kecepatan sebuah line dalam proses pembuatan sepatu per jam.Informasi ini di tampilkan berdasarkan hasil produksi perjam yang dikerjakan oleh setiap line yang ada di dalam sebuah plant.Informasi ini digunakan untuk menentukan line mana yang akan melakukan lembur atau offertime dalam sebuah plant.

12. Dashboard export menampilkan data untuk kebutuhan eksport dan proses produksi.Alur proses untuk export mulai dari cutting,sewwing , assembling,finish goods, exports .Jika persentase di setiap proses kurang dari $100 \%$ maka managemnet harus menambah offer time agar export dapat sesuai schedjule dan tidak terlambat.

\section{KESIMPULAN}

Penelitian pengembangan sistem informasi eksekutif dashboard monitoring produksi dapat disimpulkan sebagai berikut:

1. Pengembangan sistem informasi eksekutif dashboard monitoring produksi di PT KMK Global Sports telah dapat dilaksanakan, dan sistem tersebut telah berfungsi dengan baik yang ditunjukkan dengan tersedianya kecepatan informasi yang diperoleh dalam bentuk dashboard maupun laporan-laporan kegiatan produksi sepatu dalam bentuk tayangan grafik dan juga dapat dicetak, sehingga tersedia layanan informasi yang cepat, akurat dan effisien. Infomasi yang dihasilkan dari eksekutif dashboard monitoring produksi juga dapat digunakan manajemen PT KMK Global Sports sebagai salah satu dasar pengambilan keputusan strategis. 
2. Sistem informasi eksekuitf dashboard monitoring produksi yang dihasilkan telah teruji kualitasnya dan dapat memenuhi kebutuhan pengguna, proses pengujian eksekuitf dashboard monitoring produksi menggunakan pengujian sistem berdasarkan ISO 9126 dan metode pengujian black-box testing.

\section{SARAN}

Berkaitan dengan pengembangan eksekuitf dashboard monitoring produksi ini dapat diberikan saran sebagai berikut:

1. Sebaiknya sistem eksekuitf dashboard monitoring produksi PT KMK Global Sports dapat dikembangkan dalam bentuk aplikasi mobile divice (android/windows mobile base,Iphone) agar proses akses yang dilakukan pengguna akan jauh lebih mudah.

2. Sistem executive dashboard monitoring produksi merupakan alat bantu pembuatan perencanan, pengambilan keputusan dan pelaporan kegiatan produksi PT KMK Global Sports yang cukup efisien, sehingga disarankan Manajemen dapat menyampaikan ke departemen lain yang sejenis, baik dalam satu perusahaan atau perusahaaan lain untuk dapat mengimplementasikan sistem sejenis.

\section{DAFTAR PUSTAKA}

[1] Sukirno, Sadono. 2002. Teori Mikro Ekonomi. Cetakan Keempat Belas. RajawaliPress: Jakarta.

[2] Joesron Suhartati dan Fathorrozi,2003, Teori Ekonomi Mikro : Salemba Empat, Jakarta.

[3] Soleh., Dewi, Amalya, Meta., Arfiah., Asdin., 2013, Metode Peninjauan DashboardDari Business Inteligence Untuk membuat Keptusan Lebih Baik. Prosiding Seminar Nasional Teknologi Informasi dan Multimedia, STMIK Amikom, Yogyakarta.

http://ojs.amikom.ac.id/index.php/semnasteknomedia/article/view/5 49. Diakses 22 September 2017.

[4] Turban, Efraim., 2011, Decision Support and Business Intelligence System, 9th edition. New Jersey, Pearson Education Inc.

[5] Henderi., Suprianti, Ruli., 2014, Model Sistem Executive Digital Dashboard Untuk Perguruan Tinggi. KNSI2014-144,

https://www.academia.edu/6273341/Model_sistem_executive_digital_dashboard _untuk_perguruan_tinggi. Diakses 25 Agustus 2017.

[6] Padita, Oktavianus, Bernadus, Anderson., Nugroho, Adi, Hanung., Santosa, Insap, Paulus., Model Pengembangan Dashboard Berbasis User Centered Design,SNIK 2015, Semarang, 2015.

http://ilkom.unnes.ac.id/snik/prosiding/2015/20.\%20Anderson.pdf. Diakses 2 September 2017.

[7] Soleh., Dewi, Amalya, Meta., Arfiah., Asdin., 2013, Metode Peninjauan Dashboard Dari Business Inteligence Untuk membuat Keptusan Lebih Baik. Prosiding Seminar Nasional Teknologi Informasi dan Multimedia, STMIK Amikom,

Yogyakarta.http://ojs.amikom.ac.id/index.php/semnasteknomedia/article/view/5 49. Diakses 22

September 2017

[8] Anggoro, Dani., Aksani, Luthfi, Muhamad.,Dashboard Information System Sebagai Pendukung Keputusan Dalam Penjualan Tiket Pesawat Studi Kasus: PT.Nurindo Tour. Jurnal Sistem Informasi, Univ Budi Luhur, Vol 5, No 3,Maret 2015. http://si.its.ac.id/data/sisfo_data/files/8_vol5no3.pdf. Diakses 22 September 2017.

[9] Kurniawan, Yohanes., Devyano Luhukay, dan Titan Titan, Tahun 2013, Perancangan Sistem Monitoring dan Evaluasi Bantuan Usaha Pertanian pada Kementrian Pertanian RI, Jurnal ComTech Vol.4 No. 2.

[10] Chowdhary, Pawan., Palpanas, Themis., Pinel, Florian., Chen, Kwei, Shyh., Wu, Y, Freederic., Model Driven Dashboards for Business Performance Reporting.Jurnal IEEE,

DOI:10.1109/EDOCS.2006.34, 2006.http://ieeexplore.ieee.org/document/4031224/. Diakses 2

September 2017.

[11] Gounder, S, Mohan., Iyer, Vasudevan, Vani., Mazyad, Al, Abdulaziz., A Survey on Business Inteligence Tools for University Dashboard Development. Jurnal IEEE, DOI: 
10.1109/ICBDSC.2016.7460347, Date of Conference: 15-16 March 2016.

http://ieeexplore.ieee.org/document/7460347/. 2 September 2017.

[12] J, Mary, Sengol., S, Usha., 2015, Web Based Document Management System in Life Science Organization. IEEE Journal, DOI: 10.1109/GET.2015.7453826,

http://ieeexplore.ieee.org/document/7453826/, Diakses 25 Agustus 2017.

[13] Giovani, De, Enrico., Flesca, Sergio., Folio, Antonietta., Guarasci, Roberto., Sorrentino, Elisa., 2015, Digital Document Copies and Duplicates. IEEE, ISBN: 978-1-4673-6831-5. DOI:

10.1109/ICDIPC.2015.7323042, http://ieeexplore.ieee.org/document/7323042/. Di-Diakses 24 Maret 2017.

[14] Ochca, F, Sergio., Rossel, O, Pedro., Bastarica, Cecilia Maria., A Software Architecture to Support Digital Document Interchange for the Cliean Goverment. DOI: 10.1109/ICACT.2006. 2006441, Date of Conference: 20-22 Feb 2006, IEEE, 2015.

http://ieeexplore.ieee.org/document/1626046/. 2 September 2017. 